\section{Paradigm lost}

SIR - Christopher Exley's wistful reflections on the redefining of basic science (Nature 364, 276; 1993) deserve serious consideration. His letter reminds us clearly of the chronic frustration and demoralization experienced by academics engaged in the pursuit of knowledge for its own sake. What seems to me to strike at the heart of this despondency is not so much the lack of funds and poor professional standing - although these clearly are important factors - but the emptiness that accompanies the realization that the incessant privatization of basic science is often at the expense of individual creativity. It is as if the very essence of academic research has become a stigma.

I can only assume that the advocates of current policies would like to disarm fundamental research, and its inherent unpredictability, in favour of a virtual reality based on scientific clairvoyance. The fundamental flaw in this approach is that the personal needs and aspirations of talented people to express their scientific creativity are incommensurate in the long term with preordained visions of technological exploration. In a similar vein, the current move towards the straitjacketing of postgraduate training in the United Kingdom will deny young people the opportunity to experience the underlying aesthetic quality of scientific discovery. It is my contention that, without this experience, new advances in science will become curtailed because such a policy offers little that is innovative within the sphere of the individual.

The freedom to follow up one's curiosity, to think laterally, to (dare I say it) "play", are important prerequisites for basic research that cannot be discounted if new knowledge is to be realized. The fact that this is a paradigm lost will not only serve to undermine the future exploitation of science for economic gain but is a serious unjustified impoverishment of the cultural vitality of industrialized nations.

\section{Stephen Mann}

University of Bath,

School of Chemistry,

Claverton Down,

Bath BA2 7AY, UK

SIR - Philip Siekevitz, in his letter headed "Love or money"? (Nature 364, 477 ; 1993), notes the growing habit of pharmaceutical companies who buy the rights to exploit the scientific findings of independent research institutes, many of which have long received substantial support from public monies, rather than fund basic research in their own organizations. $\mathrm{He}$ also eloquently bemoans the continued privatization of science by researchers who see in their own work the glimmer of personal profit and then goes on to ask "What has become of the love of science, of research, of simple satisfaction with a job well done?"

What has become of those with these attributes? The sad fact is that many are no longer career scientists because of the lack of continuing public support for their science; some of us spend increasing amounts of potential research time competing for the scarce public dollars still available; and the remainder, as Siekevitz notes, sell themselves to the highest bidder. In my experience, most of these latter individuals are not driven by greed, but rather, as we all are, by the desire to continue the personal quest for basic answers to some of Nature's most important questions. However, as public support of basic science continues to shrink in real dollars, more and more of the existing science enterprise is, in effect, put on the block. After all, pharmaceutical companies cannot buy what has not already been devalued, abandoned and, in effect, put up for sale.

I recently returned from a meeting sponsored by the US National Science Foundation (NSF) for directors of its

\section{Non Angli . . .}

SIR - Your leading article (Nature 364, 745; 1993) makes a number of important and valid points about the decline in the numbers leaving school with the qualifications expected for the study of science and engineering in British universities. Inconsistency and the promulgation of incompatible policies are, however, characteristics that we have grown accustomed to expect from this administration.

One of the issues that you discuss at length is the inadequacy of the A-level system. Such problems are not, of course, "British" as you state, but particular to England and Wales. How many times do London-based journalists have to be reminded that here in Scotland - a part of Britain - there is a different education system, with five 'highers' being the normal programme of study for entrance to universities?

The system of 'highers', with clear weaknesses of its own, attempts to address the central concern with A-levels expressed by those in England and Wales. Students with 'highers' have been known to gain entrance to universities south of the border, as well as in Scotland, although in general the Scottish university institutions adjust to the different knowledge base of such students through a longer course of study.

\section{Paul Trayhurn}

Division of Biochemical Sciences,

Rowett Research Institute,

Bucksburn,

Aberdeen AB2 9SB,

Scotland, UK
Research Experiences for Undergraduates Program. This programme, designed and funded by NSF in the hope that it will have a positive impact on career choices in science, annually provides hundreds of college students with the opportunity to participate directly in the research enterprise by placing them in laboratories in universities and research institutes across the nation.

Siekevitz would be pleased to know that love of science continues to be a strong motivator for most of these students. However, many of them say that they will not pursue this path because of the growing perception that a career in basic science is not an appropriate choice for those who also need the money.

Tragically, for most of us, it has never been a question of "love or money?", but like many other areas of human enterprise it remains, love and money.

Robert J. O'Connell

Worcester Foundation

for Experimental Biology,

222 Maple Avenue,

Shrewsbury,

Massachusetts 01545, USA

\section{Fair shares}

SIR - In recent issues of Nature there has been increasing comment about ways in which the current falling levels of postgraduate students could be halted. From my time as a student I feel that one of the most important parts of being a research student is to feel that one is an 'accepted' scientist. One of the best ways to achieve this is by presentation of the student's work at scientific congresses. I feel, however, that the old idea of a research group attending as a unit is rapidly being replaced by either the principal researcher or a single student attending because of the exorbitantly high costs now being charged by professional congress agencies. For example, at a forthcoming congress in my research field, it will cost DM1,600 per person ( $£ 640$ ) to attend, at the cheapest rates and not using air travel. That comes to more than $£ 2,500$ for our small group. This is a sizeable amount and restricts attendance to one meeting a year or one delegate per congress, often the principal investigator. This restriction equally applies to researchers from Eastern Europe, or when air travel is involved.

Perhaps it is time that congresses were once again held at universities rather than city centre hotels in popular cities or resorts with the subsequent higher costs entailed?

William Brooks

Institute for Surgical Research, Ludwig-Maximillians-University. Klinikum Grosshadern, 81366 Munich.

Germany

NATURE · VOL 365 • 28 OCTOBER 1993 